\title{
ISOLATED TRAUMATIC PROXIMAL TIBIO-FIBULAR JOINT DISLOCATION: CASE REPORT OF A RARE INJURY
}

Kumar $\mathrm{V}^{1}$, HariHaran ${ }^{1}$, Goyal $\mathrm{S}^{1}$, Oliveira $\mathrm{M}^{1}$

\begin{abstract}
We report a rare case of isolated traumatic anterolateral dislocation of proximal tibiofibular joint dislocation in a 41 year old female patient who was admitted in our institution following a twisting injury to knee. Initial clinical examination and plain radiographs were equivocal needing bilateral axial Computed Tomography (CT) scan for definite diagnosis. We discuss the various aspects of this rare injury including the current management options and clinical outcome.
\end{abstract}

KEY WORDS : Dislocation, Tibiofibular joint, Knee injury

1. Department of Trauma and Orthopaedics, St. Richards Hospital, Chichester, United Kingdom

\section{For Correspondence}

Mr.Vijaya Kumar

Department of Trauma and Orthopaedics,

St. Richards Hospital, Chichester, United Kingdom

E-mail: vijaysuma3@yahoo.co.uk 


\section{INTRODUCTION}

Isolated traumatic dislocations of the proximal Tibio-fibular joint are rare and difficult to diagnose. Uncertainty continues regarding definitive management of these complex injuries. The diagnosis can be easily missed clinically and after plain radiographic imaging particularly in patients with increased Body Mass Index (BMI) and in untrained eyes of inexperienced practioners. Missed injuries can lead to chronic pain and recurrent dislocation. The aim of this case report is to create the awareness among practicing doctors who can potentially miss this injury due to difficulty in interpretation of routine radiographs resulting a long lasting disability.

\section{CASE REPORT}

A 41-year-old lady with relatively high BMI was admitted to our accident and emergency department in September 2012 following a slip in mud having twisted the left knee and hyperplantar flexed the left ankle. Clinical and radiological examination of the ankle did not reveal any significant injury. Examination of the knee revealed pain, mild swelling and tenderness over the lateral aspect combined with an inability to fully extend the knee. Neurovascular status distal to the injury was intact. There were no signs of generalised hyper laxity. Bony landmarks were difficult to palpate due to the swelling and patient's body habitus. Routine (AP \& Lateral) $\mathrm{x}$ rays of the knee did not reveal any obvious bony injury although the oblique views were suspicious of subluxation of the proximal Tibio-fibular joint (Figure 1).

\section{Figure 1: Plain radiographs AP, lateral and oblique}

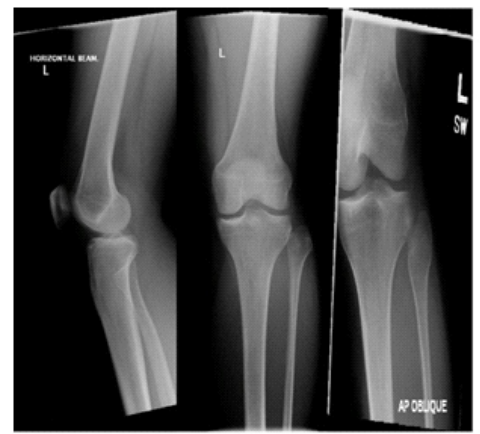

The CT scan of both knees was conducted to compare both sides, which confirmed the diagnosis of anterolateral dislocation of the proximal tibio-fibular joint. An initial attempt to reduce the dislocation under sedation in accident and emergency was unsuccessful. The patient was subsequently taken to the operating theatre where another attempt of closed reduction under general anaesthesia was attempted without success leading to open reduction and internal fixation of the dislocation. Interposition of the soft tissues (particularly capsular and interosseous ligament) explained previous failures of closed reduction. These tissues required release for a successful open reduction. There was no gross instability after the reduction. However, on stressing the joint, a mild subluxation was noted needing repair of capsular tissue and the Interosseous ligament reinforced with a temporary screw (Figure 2).

\section{Figure 2: Post-op radiographs}

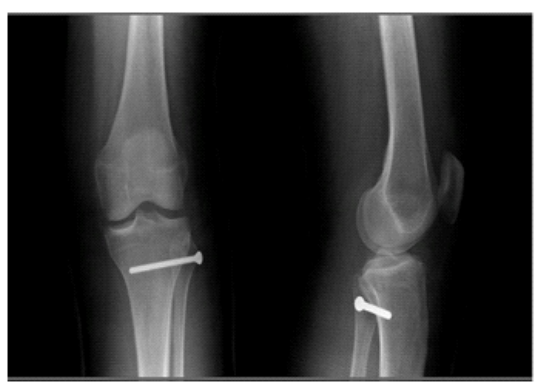

The reduction was confirmed via image intensifier. Postoperatively, a non-weight bearing, above knee cast was applied for three weeks. A gentle range of movements was initiated with physiotherapy. Partial weight bearing was initiated at six weeks until the temporary screw was removed at 10 weeks. Full weight bearing with intense physiotherapy started at this stage. The patient was regularly followed up in orthopaedic outpatient clinics at 1, 2, 3,6 and 12 months with follow up radiographs. At final follow up the patient was completely pain free and fully weight bearing with near full range of movements in the affected knee and satisfactory radiographs

\section{DISCUSSION}

This case report has been discussed under following headings.

Anatomy: The proximal tibiofibular joint is a synovial joint that functions in dissipating lower leg torsional stresses and lateral tibial bending moments and in transmitting axial loads in weight-bearing. It communicates with the knee joint in approximately $10 \%$ of adults, although communication in up to $64 \%$ has been reported with MR arthrogram and has been construed as the "fourth compartment" of the knee joint. ${ }^{1}$ A fibrous capsule surrounds PTF joint articulation and is strengthened by anterosuperior and posterosuperiortibio fibular ligaments.

Classification: Ogden (based on Lyles original classification) described following descriptive terms. ${ }^{2}$

1 - Subluxation

2 - Dislocation 
a - anterolateral most common $(85 \%)$

b-posteromedial

c-superior

- typically preadolescent females

- may have generalized ligamentous laxity or CTD

We noted anterolateral dislocation in our case.

Mechanism: PTFJ is inherently stable joint. This injury occurs with knee in flexion, the ankle is plantar-flexed and inverted. In this position relaxes the stabilizing structures including LCL, predisposing to lateral dislocation. This mechanism was noted by Turco et al. in all his patients. ${ }^{3}$ This was the case with our patient.

Diagnosis: Diagnosis is mainly based on history, physical examination and adequate radiographs. Since it is not a common injury, it can be easily missed without suspicious mind and untrained eyes with plain radiographs. It is easy to miss this injury in poly trauma patient. Clinical signs may be subtle. Even though plain radiographs in multiple planes are useful but sometimes can be uncertain. Keogh et al. opines that plain radiographs are inconsistent in aiding diagnosis and suggests that axial CT scan is investigation of choice. ${ }^{4,5}$ In article by Voglino et al. suggests that in addition to good quality x-rays, CT scans are useful in resolving diagnostic uncertainty. ${ }^{6}$ We agree with above authors that axial CT is very helpful in solving the diagnostic uncertainty and ruling out an associated fracture. We also strongly believe that the accuracy improves with bilateral comparative axial CT scan (Figure 3) rather than single side.

\section{Figure 3: Bilateral axial CT scan}

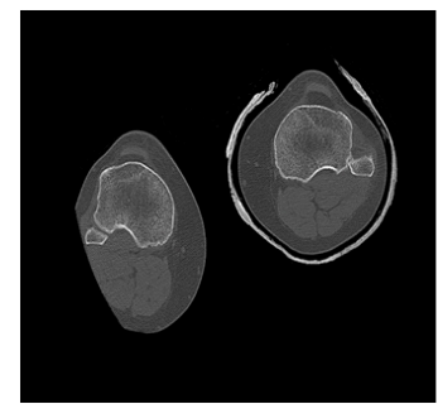

Treatment: Various treatment options are described ranging from closed reduction, casting and early mobilisation to open reduction and internal fixation in irreducible and chronic dislocations. $^{7-11}$

Surgical option for acute injuries includes K-Wire fixation, syndesmotic screw fixation, tightrope device and biceps femoris and Gracilis tendon reconstruction. ${ }^{12,13}$ For chronic instability, the options include arthrodesis, resection of fibular head and tendon reconstruction. ${ }^{14}$

In acute injuries, closed reduction can be attempted but can be unsuccessful even under general anaesthesia due to interposition of soft tissues. This may require open reduction. The common technique described is to flex the knee to relax LCL, Dorsiflexion of the foot which relaxes the interosseous membrane and antero-posterior manual pressure on fibular head. ${ }^{15}$ After successful reduction, immobilisation in an above knee plaster for two to three weeks followed by functional rehabilitation is recommended. ${ }^{16}$ However, this post-operative regimen is not unanimously supported. Other authors suggest immobilisation for six weeks. ${ }^{17}$ There is also still debate regarding the optimal time to remove the transfixation screw. In our case study, we immobilised with an above knee cast for three weeks until wound healing, which was followed by range of movement physiotherapy and touch weight bearing started. Partial weight bearing started at six weeks. The trans fixation screw was removed at ten weeks post-operative and full weight bearing with aggressive physiotherapy was started. We believe that prolonged immobilisation is unnecessary when stabilisation is performed.

In chronic injuries, arthrodesis leads to restricted range of movements, osteoarthritis and ankle pain. Fibula head excision is an option in an adult but not indicated in athletes or children $^{18}$ since several important stabilising structures (LCL, Biceps femoris Tendon, proximal Tibio-fibular ligament) are attached to it. Ligament reconstruction is a reasonable option in these cases. ${ }^{19}$ In our case, the patient has not experienced any instability at final follow up

Educational Message: Acute traumatic dislocation of the proximal tibio-fibular joint is a rare injury, which can be easily missed. One needs to be clinically suspicious about this injury while examining a patient with knee and ankle injury. Plain radiographs are susceptible to interpretation difficulty, yet remain useful to experienced practitioners. Bilateral axial CT is more informative and diagnostic. Missed injuries can lead to long term disability and pain. Early correct diagnosis and management is crucial in improving the outcome of this injury.

\section{REFERENCES}

1. Bozkurt M, Yilmaz E, Atlihan D, Tekdemir I, Havitçioğlu H, Günal I. The proximal tibiofibular joint: an anatomic study. ClinOrthop Relat Res. 2003 Jan;(406):136-40.

http://dx.doi.org/10.1097/00003086-20030100000022

PMid: 12579012 
2. Ogden JA. Subluxation and dislocation of the proximal tibiofibularjoint. J Bone Joint Surg Am. 1974;56:145-54. PMid: 4812157

3. Turco VJ, Spinella AJ. Anterolateral dislocation of the head of the fibula in sports. Am J Sports Med. 1985;13:209-15. http://dx.doi.org/10.1177/036354658501300401

4. Keogh P, Masterson E, Murphy B, McCoy CT, Gibney RG, Kelly $E$. The role of radiography and computed tomography in the diagnosis of acute dislocation of the proximal tibiofibular joint.Br JRadiol. 1993;66:108-11. http://dx.doi.org/10.1259/0007-1285-66-782-108 PMid: 8457820

5. Horan J, Quin G. Proximal tibiofibular dislocation, Emerg MedJ. 2006;23:e33.

http://dx.doi.org/10.1136/emj.2005.032144PMid:16627827 PMCid: PMC2564106

6. Voglino JA, Denton JR. Acute traumatic proximal tibiofibular joint dislocation confirmed by computed tomography. Orthopaedics 1999;22:255-8.

7. Horan J, Quin G. Proximal tibiofibular dislocation. Emerg MedJ 2006;23:e33.

http://dx.doi.org/10.1136/emj.2005.032144PMid:16627827

PMCid: PMC2564106

8. Parkes JC 2nd, Zelko RR. Isolated acute dislocation of the proximal tibiofibular joint.Case report. J Bone Joint Surg Am. 1973;55:17783PMid:4691655

9. Ellis C. A case of isolated proximal tibiofibular joint dislocation while snowboarding. Emerg Med J 2003;20:5634.

http://dx.doi.org/10.1136/emj.20.6.563

PMid:14623856 PMCid:PMC1726224

10. Halbrecht JL, Jackson DW.Recurrent dislocation of the proximal tibiofibular joint.Orthop Rev 1991;20:957-60PMid:1749660

11.Robinson Y, Reinke M, Heyde CE, Ertel W, Oberholzer A. Traumatic proximal tibiofibular joint dislocation treated by open reduction and temporary fixation: a case report. Knee Surg Sports TraumatolArthrosc 2007; 15:199201 http://dx.doi.org/10.1007/s00167-006-0147-1PMid:16858561
12.Lenehan B, McCarthy T, Gilmore M. Dislocation of the proximal tibiofibular joint, a new method of fixation. $J$ Injury Extra 2006;37:3859.

http://dx.doi.org/10.1016/j.injury.2006.02.058

13.Luscombe K, Maffulli N. Stabilization of the superior tibiofibular joint. Tech Knee Surg 2005;4:12630

http://dx.doi.org/10.1097/01.btk.0000164754.96904.a3

14. Sekiya JK, Kuhn JE. Instability of the proximal tibiofibular joint. J Am AcadOrthopSurg 2003;11:1208.PMid:12670138

15.Robinson Y, Reinke M, Heyde CE, Ertel W, Oberholzer A. Traumatic proximal tibiofibular joint dislocation treated by open reduction and temporary fixation: a case report. Knee Surg Sports TraumatolArthrosc. 2007; 15:199-201. Epub 2006 Jul 21. http://dx.doi.org/10.1007/s00167-006-0147-1PMid:16858561

16.van den Bekerom MP, Weir A, van der Flier RE. Surgical stabilisation of the proximal tibiofibular joint using temporary fixation: a technical note.ActaOrthop Belg.2004;70:604-8. PMid: 15669464

17. Aladin A, Lam KS, Szypryt EP. The importance of early diagnosis in the management of proximal tibiofibular dislocation: a 9- and 5-year follow-up of a bilateral case. Knee. 2002 Sep;9(3):233-6. http://dx.doi.org/10.1016/S0968-0160(02)00012-1

18.Thomason PA, Linson MA. Isolated dislocation of the proximal tibiofibular joint.J Trauma. 1986;26:192-5.

http://dx doi.org/10.1097/00005373-198602000-00018

19 Giachino AA.Recurrent dislocations of the proximal tibiofibular joint.Report of two cases. J Bone Joint Surg Am. 1986;68:1104-6. PMid:3745254 